\title{
Thermal conductivities, thermal diffusivities, and volumetric heat capacities of core samples obtained from the Japan Trench Fast Drilling Project (JFAST)
}

\author{
Weiren Lin ${ }^{1 *}$, Patrick M Fulton ${ }^{2}$, Robert $N$ Harris ${ }^{3}$, Osamu Tadai ${ }^{4}$, Osamu Matsubayashi ${ }^{5}$, Wataru Tanikawa ${ }^{1}$ \\ and Masataka Kinoshita ${ }^{1}$
}

\begin{abstract}
We report thermal conductivities, thermal diffusivities, and volumetric heat capacities determined by a transient plane heat source method for four whole-round core samples obtained by the Japan Trench Fast Drilling Project/Integrated Ocean Drilling Program Expedition 343. These thermal properties are necessary for the interpretation of a temperature anomaly detected in the vicinity of the plate boundary fault that ruptured during the 2011 Tohoku-Oki earthquake and other thermal processes observed within the Japan Trench Fast Drilling Project temperature observatory. Results of measured thermal conductivities are consistent with those independently measured using a transient line source method and a divided bar technique. Our measurements indicate no significant anisotropy in either thermal conductivity or thermal diffusivity.
\end{abstract}

Keywords: Thermal conductivity; Thermal diffusivity; Volumetric heat capacity; Anisotropy; Core sample measurement; JFAST

\section{Findings}

\section{Background}

The 2011 Mw 9.0 Tohoku-Oki, Japan, earthquake produced a maximum coseismic slip of $>50 \mathrm{~m}$ near the Japan Trench in the Miyagi-Oki region, triggering a huge tsunami (Fujiwara et al. 2011; Lay et al. 2011). To understand the reasons for the large displacement of the coseismic slip, the Japan Trench Fast Drilling Project (JFAST, Integrated Ocean Drilling Program (IODP) Expedition 343 and 343T) drilled through the plate boundary fault zone that ruptured during the Tohoku-Oki earthquake. This work was undertaken by the drilling vessel $(D / V)$ Chikyu, approximately 1 year after the earthquake at Site C0019 (Mori et al. 2012; Chester et al. 2012), and one of the principal objectives of JFAST was to detect the residual temperature anomaly

\footnotetext{
* Correspondence: lin@jamstec.go.jp

'Kochi Institute for Core Sample Research, Japan Agency for Marine-Earth Science and Technology (JAMSTEC), 200 Monobe-otsu, Nankoku, Kochi, 783-8502, Japan

Full list of author information is available at the end of the article
}

induced by the coseismic frictional heat during the earthquake (Fulton et al. 2013).

To quantitatively interpret the observed $0.31^{\circ} \mathrm{C}$ temperature anomaly along the plate boundary fault and to calculate the coseismic shear stress on the ruptured fault from this thermal signal, knowledge of the thermal conductivity, thermal diffusivity, and volumetric heat capacity is necessary. Volumetric heat capacity controls how heat is manifested in terms of temperature, and thermal diffusivity controls how a heat signal diffuses over space and time. The relationship between thermal diffusivity, $\alpha$, and thermal conductivity, $\lambda$, can be expressed as follows:

$$
\alpha=\lambda / C
$$

where $C$ is the volumetric heat capacity. Obtaining measurements of any two of these parameters allows the third to be calculated.

The previous works measuring the physical properties of rocks across the Tohoku-Oki fault zone have focused on thermal conductivity (which is a measure 
of a material's ability to transfer heat and has a primary control on the background geothermal gradient) (Expedition 343/343T Scientists 2013b; Fulton et al. 2013). Determination of thermal conductivity in these studies consisted of making 45 line source measurements on split half cores (Expedition 343/343T Scientists 2013b) and 38 measurements made using a divided bar technique on rock chips (Fulton et al. 2013). Details of the divided bar thermal conductivity measurements are given in Sass et al. (1984). These techniques, however, are not suited to measuring thermal diffusivity, a key parameter for understanding the thermal decay associated with frictional heating or other transient disturbances.

In this study, we report both thermal conductivity and thermal diffusivity measurements performed on four whole-round core samples retrieved from the JFAST borehole, using a transient plane heat source method (also known as a hot-disk method). Values of thermal conductivity measured using this technique are then compared to the values previously measured. Relationships between thermal conductivity and thermal diffusivity are also found, and these allow extrapolation of the thermal properties with depth from the more extensively measured thermal conductivity values.

\section{JFAST and core samples}

The JFAST Drilling Site C0019 is located within an area of large shallow slip, approximately $93 \mathrm{~km}$ seaward of the $2011 \mathrm{Mw} 9.0$ Tohoku-Oki mainshock epicenter, and approximately $6 \mathrm{~km}$ landward of the trench axis (Figure 1). Site C0019 is located directly above a horst block, approximately $1.2 \mathrm{~km}$ west of a normal-fault boundary between the horst and adjacent graben centered under the trench. At this location, the three boreholes drilled over a small area (the largest distance between them is approximately $30 \mathrm{~m}$ ) successfully penetrated the interface between the subducting Pacific Plate and the overriding North American Plate. These boreholes thus enabled geophysical logging, core sampling, and long-term temperature monitoring (Expedition 343/343T Scientists 2013a; Lin et al. 2013; Chester et al. 2013; Fulton et al. 2013).

However, due to time constraints the coring operations were limited. Four separate depth intervals at over $137 \mathrm{~m}$ between 177 and 845 meters below the seafloor (mbsf) were cored. This process resulted in the collection of 21 cores with a total length of approximately $53 \mathrm{~m}$ from borehole C0019E. Inspection of these cores yielded seven lithologic units (Figure 2), and the characteristics of each unit have now been described (Expedition 343/343T Scientists 2013c). Logging while drilling (LWD) data and core observations reveal abrupt structural and lithologic changes at approximately $820 \mathrm{mbsf}$, where the presence of a $<5$-m-thick scaly-clay layer marks the plate boundary decollement (Chester et al. 2013). This scaly-clay layer separates the deformed sediments of the prism above from the relatively undisturbed pelagic strata and igneous oceanic crust of the subducting Pacific plate below. The cores taken from the prism generally consist of clayey to silty mudstones comprising terrigenous silt and clay, vitric ash, and biogenic siliceous fragment, with variable steeply dipping bedding. In contrast, the underthrust sediments consist of well-bedded mudstones and pelagic clay, with shallow bedding dips $\left(<30^{\circ}\right)$ (Expedition 343/343T Scientists 2013c).

In this study, we report three thermal properties: thermal conductivity, thermal diffusivity, and volumetric heat capacity, which were resolved using a transient plane heat source method. The values were determined for four whole-round core samples retrieved from borehole C0019E at depths of 177 mbsf in lithologic unit 1, $697 \mathrm{mbsf}$ and $802 \mathrm{mbsf}$ in unit 3, and $828 \mathrm{mbsf}$ in unit 5 (Figure 2). The shallower three samples were derived from the frontal prism of the overriding plate, that is, in the hanging wall of the plate boundary fault, and the deepest sample from lithologic unit 5 in the foot wall of the fault. The shallowest sample (no. 1 from approximately $177 \mathrm{mbsf}$ ) has the largest porosity of approximately $67 \%$ (Table 1), and the three deeper samples (approximately 697 to $828 \mathrm{mbsf}$ ) have porosities of approximately $45 \%$. The deepest sample from the subducting Pacific Plate is found to have a lower bulk density (wet) and lower grain density than the others (Table 1), and this is considered to be related to its different mineralogic composition.

\section{Measurements of thermal conductivity and thermal diffusivity \\ Methods}

We applied the transient plane heat source method (Gustafsson 1991; ISO 2008) to measure thermal conductivity and thermal diffusivity and then computed the volumetric heat capacity (specific heat capacity per unit volume). In this study, we used the commercial thermal constants analyzer TPS 1500 (Hot Disk, Gothenburg, Sweden). Our analysis is based on embedding a hot disk probe within a sample such that the material sample above and below the plate each approximates a halfspace (Figure 3). The hot disk probe was used as both a heating plate (source) and a dynamic temperature sensor. The heating plate has a diameter of $13 \mathrm{~mm}$, a negligible heat capacity, and transiently heats the material while recording temperature as a function of time (Gustafsson 1991; ISO 2008). The probe is constructed of very thin metal foil (nickel) and covered on both sides by thin insulating polyimide film; it has a total thickness of approximately $50 \mu \mathrm{m}$. An electrical current in the form of a step function was applied to the heating plate to generate a heat pulse for a duration of $20 \mathrm{~s}$, which resulted in a 


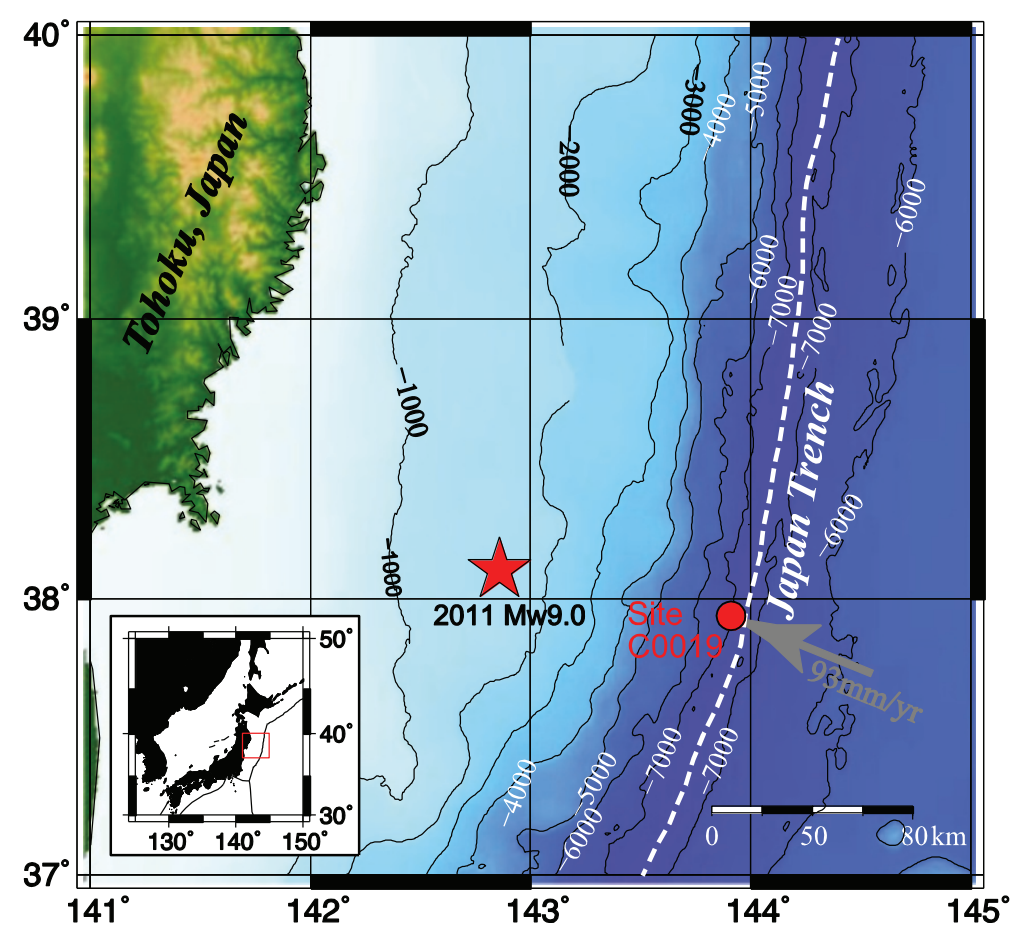

Figure 1 Location of JFAST Site C0019. Red star shows the epicenter of mainshock of the 2011 Mw 9.0 Tohoku-Oki earthquake; gray arrow shows relative plate motion at the JFAST location (Argus et al. 2011).

temperature increase of $1^{\circ} \mathrm{C}$ to $2^{\circ} \mathrm{C}$ in this study. The time variation in temperature was then recorded by the hot disk probe, and this is known to depend on values of both thermal conductivity, $\lambda$, and thermal diffusivity, $\alpha$. Such values are determined by fitting the increasing temperature curve using least-squares analysis (ISO 2008). Consequently, the third thermal property, volumetric heat capacity, can be obtained by dividing thermal conductivity by thermal diffusivity (using Equation 1).

The thermal constants analyzer TPS 1500 has two measurement modes. The first assumes that the test sample is isotropic and calculates both bulk thermal conductivity and bulk thermal diffusivity. The second mode allows anisotropic measurements and gives values of thermal conductivity and thermal diffusivity in both the radial direction (a horizontal direction in the original position of the core samples) and the axial direction (vertical direction). We obtained measurements using both modes, as discussed below.

The thermal property measurements were conducted at room temperature (at approximately $23^{\circ} \mathrm{C}$ ) and at atmospheric pressure. Using the measurement apparatus referred to above and the environmental conditions specified, the reported measurement precision (reproducibility) for thermal conductivity, thermal diffusivity, and volumetric heat capacity using the bulk mode have been found to be better than $2 \%, 5 \%$, and $7 \%$, respectively (Hot Disk 2007a). In addition, both precision for thermal conductivity and thermal diffusivity using the anisotropic mode have been found to be $5 \%$ (Hot Disk 2007b).

To demonstrate that the apparatus was working correctly and for calibration, we measured thermal conductivity and thermal diffusivity in both bulk and anisotropic measurement modes for a pair of fused isotropic silica standards. The thermal conductivity value of fused silica (1.32 to $1.33 \mathrm{Wm}^{-1} \mathrm{~K}^{-1}$, Table 2) measured in this study was found to be consistent with the value of $1.31 \pm 0.18 \mathrm{Wm}^{-1} \mathrm{~K}^{-1}$ (average and one standard deviation) previously reported in literature relating to values of fused silica at room temperature and atmospheric pressure (Horai and Simons 1969; Horai and Susaki 1989). The average values of measured thermal conductivity and thermal diffusivity in bulk mode and in anisotropic mode both in the axial and radial direction were found to be within measurement uncertainty and showed no significant anisotropy (Table 2). In addition, the one standard deviation values for the various measurements were small, suggesting higher reproducibility of this measuring system than the specification reported (Hot Disk 2007a). Based on the results of these tests, calibration of the measuring system was confirmed, and it was thus considered to be working correctly.

Prior to conducting thermal measurements, the four core samples were used for anelastic strain recovery (ASR) measurements to estimate in situ stress, using a nondestructive onboard measurement (e.g., Lin et al. 2006). To 


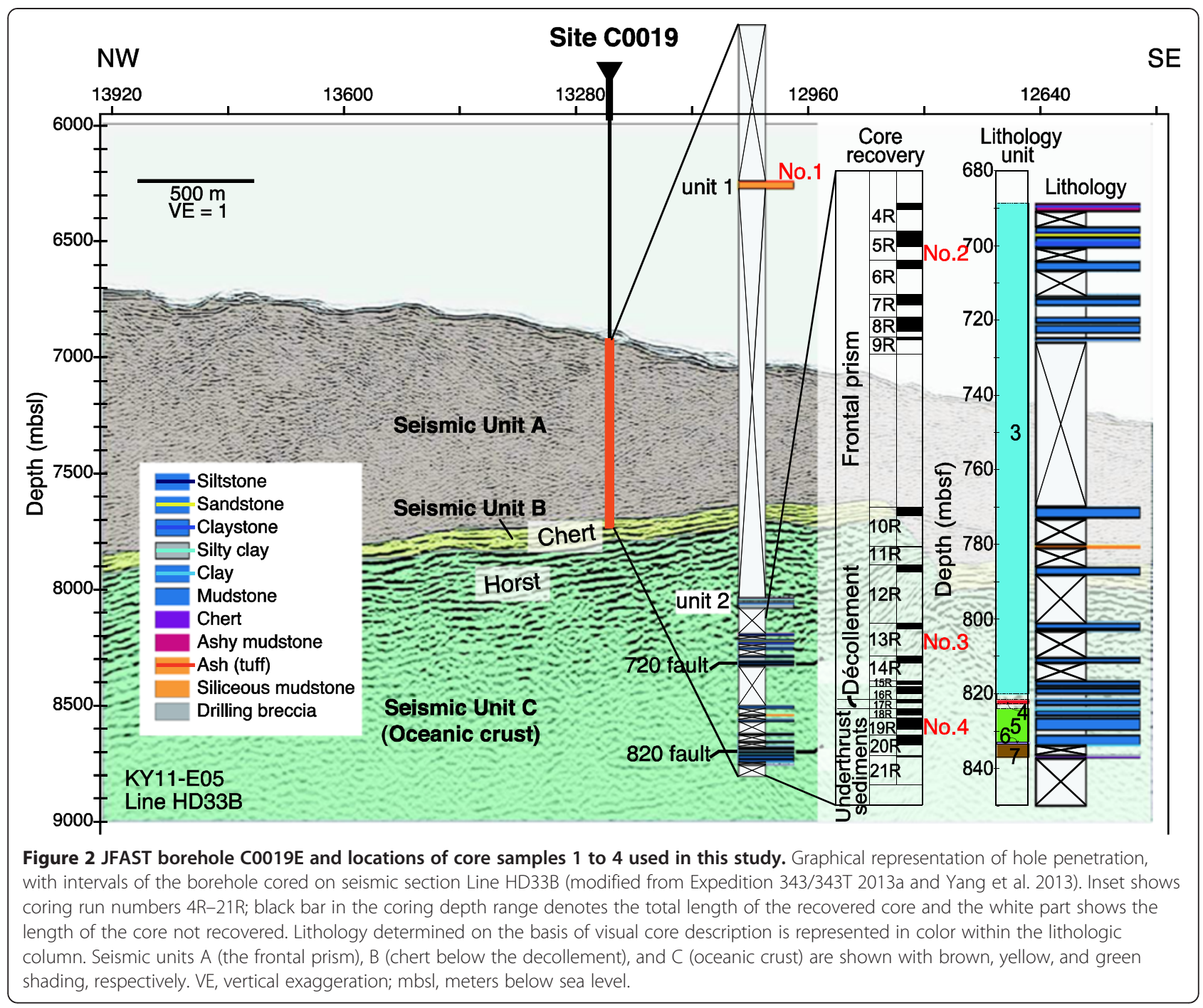

prepare our samples for measuring, they were saturated in water that had roughly the same $\mathrm{NaCl}$ solution concentration as sea water, for a period of approximately $24 \mathrm{~h}$. The core samples were then cut into two pieces perpendicular to the core axis and the thin hot disk was sandwiched between them. The sample size used had a diameter of approximately $56 \mathrm{~mm}$, (about four times the diameter of the heating plate), and each sample had a thickness of $>20 \mathrm{~mm}$. Based on a time window of $20 \mathrm{~s}$ and measured thermal diffusivities of approximately $5 \times 10^{-7} \mathrm{~m}^{2} \mathrm{~s}^{-1}$, a thermal length of about $6 \mathrm{~mm}$ was obtained, which confirmed that our sample size was sufficiently large enough to approximate a half space.

\section{Measurement results and discussion}

Thermal conductivity values measured in bulk mode using the hot-disk method ranged from 0.92 to $1.14 \mathrm{Wm}^{-1} \mathrm{~K}^{-1}$ (Table 2 and Figure 4A), where the minimum value

Table 1 Sample ID, core and section number, depth, and associated basic physical properties

\begin{tabular}{|c|c|c|c|c|c|}
\hline $\begin{array}{l}\text { Sample ID: core and section number, } \\
\text { depth in the section }(\mathrm{cm})\end{array}$ & Depth (mbsf) & Lithologic unit & $\begin{array}{l}\text { Wet bulk density } \\
\left(\mathrm{g} \mathrm{cm}^{-3}\right)\end{array}$ & $\begin{array}{l}\text { Grain density } \\
\left(\mathrm{g} \mathrm{cm}^{-3}\right)\end{array}$ & Porosity (\%) \\
\hline No. 1: 1R-1, 18-34 & $\sim 177$ & $\begin{array}{l}\text { 1, slope facies or wedge } \\
\text { sediments }\end{array}$ & 1.52 & 2.60 & 67.3 \\
\hline No. 2: 5R-1, 102-117 & $\sim 697$ & 3 , gray mudstone & 1.89 & 2.63 & 45.2 \\
\hline No. 3: 13R-1, 50-60 & $\sim 802$ & 3 , gray mudstone & 1.92 & 2.66 & 44.7 \\
\hline No. 4: 19R-2, 73-86 & $\sim 828$ & 5 , brown mudstone & 1.86 & 2.54 & 45.4 \\
\hline
\end{tabular}



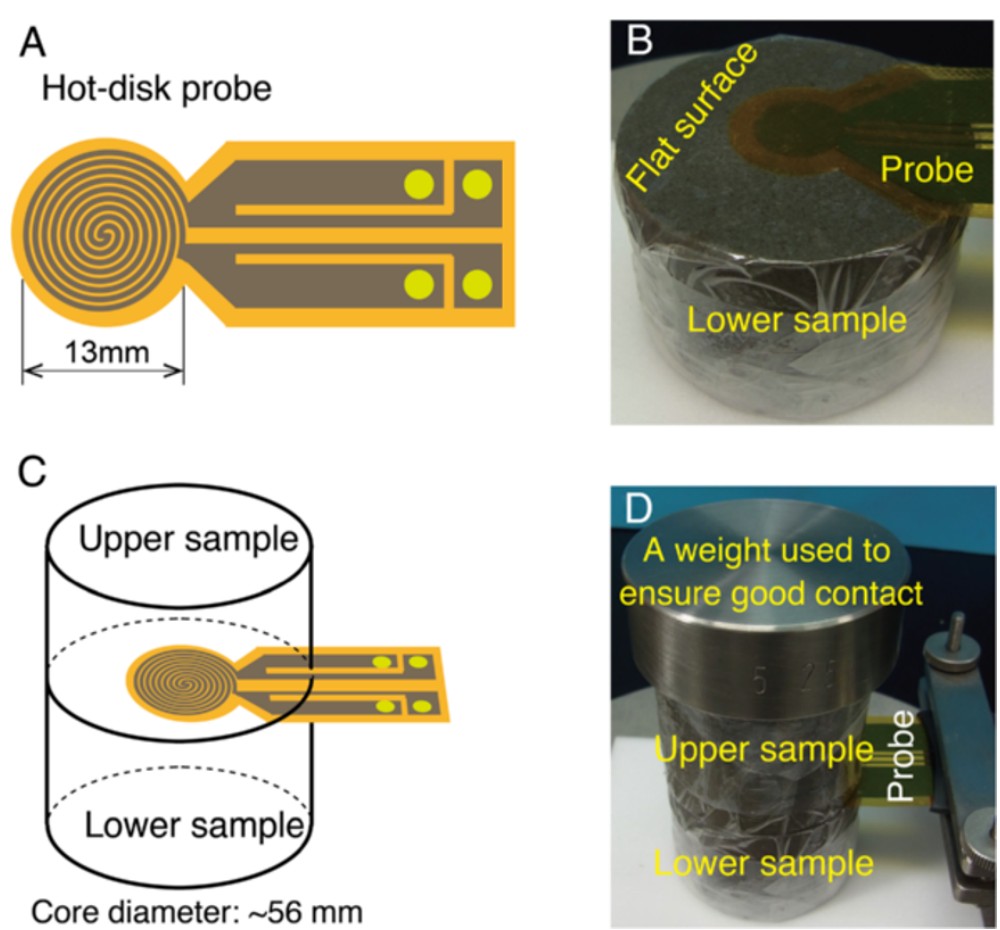

Figure 3 Hot disk transient plane heat source probe and sample assembly. Drawings ( $\mathbf{A}$ and $\mathbf{C}$ ) and photos ( $\mathbf{B}$ and $\mathbf{D}$ ) of the hot disk probe with a bifilar spiral element, representing both the plane heat source and temperature sensor and sample assembly used for thermal property measurements at room temperature and under atmospheric pressure conditions. A 500-g weight was applied on the top of the assembly to attain good contact between the core samples and the probe (D).

corresponds to the sample from the shallowest depth with the highest porosity of approximately $67 \%$ (Table 1 ) (the other three samples had porosities of approximately $45 \%)$. As the thermal conductivity of pore water is lower (typically approximately $0.6 \mathrm{Wm}^{-1} \mathrm{~K}^{-1}$ ) than that of rock-forming minerals, thermal conductivity is inversely related to porosity. However, the thermal properties were measured under atmospheric pressure conditions, and it is considered that the porosity of the core samples under atmospheric pressure may be slightly higher than under in situ pressure conditions. Lin et al. (2011) experimentally estimated the possible effects of pressure unloading on thermal conductivity for slope and upper accretionary sediments from Nankai subduction zone drilling and concluded that the thermal conductivity measured under atmospheric pressure may be underestimated by approximately $7 \%$ compared to measurements under pressure conditions representative of $1 \mathrm{~km}$ beneath the sea floor. For the deepest core sample $(828 \mathrm{mbsf})$ used in this study, the possible underestimation in thermal conductivity is therefore considered to be less than approximately $6 \%$. In addition, it is considered that the thermal properties measured at room temperature in our laboratory (approximately $23^{\circ} \mathrm{C}$ ) may differ slightly with those at

Table 2 Measurement results using hot-disk method in the four whole-round core samples and fused silica

\begin{tabular}{|c|c|c|c|c|c|c|c|c|}
\hline \multirow{2}{*}{$\begin{array}{l}\text { Sample } \\
\text { ID }\end{array}$} & \multirow{2}{*}{$\begin{array}{l}\text { Depth } \\
\text { (mbsf) }\end{array}$} & \multicolumn{3}{|c|}{ Bulk measurement } & \multicolumn{4}{|c|}{ Anisotropic measurement } \\
\hline & & $\mathrm{TC} \mathrm{Wm}^{-1} \mathrm{~K}^{-1}$ & TD $10^{-7} \mathrm{~m}^{2} \mathrm{~s}^{-1}$ & $\mathrm{VHC} \mathrm{MJm}^{-3} \mathrm{~K}^{-1}$ & $\mathrm{Ax} \mathrm{TC} \mathrm{Wm}^{-1} \mathrm{~K}^{-1}$ & Ax TD $10^{-7} \mathrm{~m}^{2} \mathrm{~s}^{-1}$ & $\operatorname{Rad} \mathrm{TC} \mathrm{Wm}^{-1} \mathrm{~K}^{-1}$ & $\operatorname{Rad}$ TD $10^{-7} \mathrm{~m}^{2} \mathrm{~s}^{-1}$ \\
\hline Fused silica & & $1.32 \pm 0.00$ & $8.27 \pm 0.00$ & $1.60 \pm 0.00$ & $1.32 \pm 0.01$ & $8.27 \pm 0.07$ & $1.33 \pm 0.01$ & $8.30 \pm 0.07$ \\
\hline No. 1 & $\sim 177$ & $0.92 \pm 0.01$ & $3.16 \pm 0.09$ & $2.92 \pm 0.09$ & $0.90 \pm 0.00$ & $3.16 \pm 0.01$ & $0.94 \pm 0.00$ & $3.29 \pm 0.00$ \\
\hline No. 2 & $\sim 697$ & $1.14 \pm 0.01$ & $3.80 \pm 0.04$ & $2.99 \pm 0.01$ & $1.11 \pm 0.01$ & $3.72 \pm 0.04$ & $1.15 \pm 0.02$ & $3.84 \pm 0.08$ \\
\hline No. 3 & $\sim 802$ & $1.05 \pm 0.01$ & $3.52 \pm 0.08$ & $2.99 \pm 0.03$ & $1.05 \pm 0.02$ & $3.50 \pm 0.08$ & $1.03 \pm 0.05$ & $3.45 \pm 0.16$ \\
\hline No. 4 & $\sim 828$ & $1.08 \pm 0.02$ & $4.43 \pm 0.06$ & $2.44 \pm 0.04$ & $1.11 \pm 0.04$ & $4.61 \pm 0.35$ & $1.07 \pm 0.03$ & $4.46 \pm 0.03$ \\
\hline
\end{tabular}

Thermal conductivity (TC) and thermal diffusivity (TD) were measured in both bulk mode and anisotropic mode respectively, and volumetric heat capacity (VHC) was calculated from the two measured thermal properties. 'Ax TC' and 'Ax TD' denote TC and TD in an axial direction in the core samples, and 'Rad' denotes the radial direction. The measured results are shown in the format of mean \pm 1 standard deviation values, and each was measured six times. 


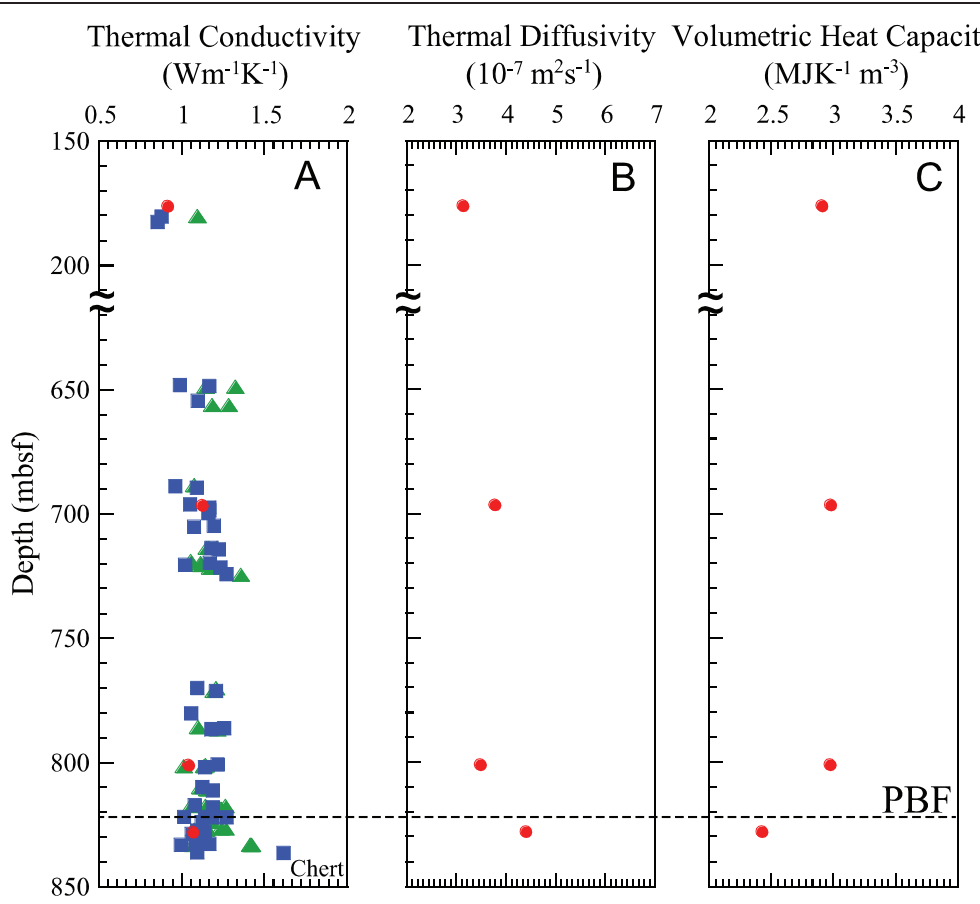

Figure 4 Depth profiles of thermal conductivity (A), thermal diffusivity (B), and volumetric heat capacity (C). Thermal conductivity values were measured for whole-round core samples (red circles), half-core samples (blue squares), and rock-chips samples (green triangles) retrieved from JFAST borehole C0019E. Thermal diffusivity (B) was measured; volumetric heat capacity (C) was calculated using the two measured values. The broken line shows the depth of the plate boundary fault (PBF) that ruptured during the 2011 Tohoku-Oki earthquake.

in situ temperature ranging approximately 10 to $25^{\circ} \mathrm{C}$ (Fulton et al. 2013).

The thermal conductivity values found in our study are consistent with the values of 45 measurements made onboard, which were conducted on split cores using a TeKa thermal conductivity half-space probe (TeKa Thermophysical Instruments - Geothermal Investigation, Berlin Germany; Expedition 343/343T Scientists 2013c), and of 38 discrete samples were measured using a divided bar system (Fulton et al. 2013) (Figure 4A). However, a significantly higher thermal conductivity value (approximately 1.6 $\mathrm{Wm}^{-1} \mathrm{~K}^{-1}$ ) was measured using the line heat source method for a chert core sample obtained from approximately 837 mbsf in lithologic unit 7 (Figure 4A).

The thermal diffusivity bulk measurements on the four core samples varied between 3.2 and $4.4 \times 10^{-7} \mathrm{~m}^{2} \mathrm{~s}^{-1}$, and some variations are greater than the reported measurement precision of different samples (Table 2 and Figure 4B). The thermal diffusivity at the shallowest depth of approximately $177 \mathrm{mbsf}$ in lithologic unit 1 (slope facies or wedge sediments) is lower, and largely reflects the influence of lower thermal conductivity therein. The other three thermal diffusivity values were determined on mudstone samples taken from 697 to 828 mbsf. These samples are considered likely to be representative of many of the depth intervals that were monitored using closely spaced temperature sensors in the adjacent observatory borehole (Fulton et al. 2013). The average thermal diffusivity for these three samples was found to be $3.92 \pm 0.5 \times 10^{-7} \mathrm{~m}^{2} \mathrm{~s}^{-1}$. Inverse modeling of the frictional heat signal observed in the JFAST observatory utilized this same range of diffusivities to estimate the amount of heat energy dissipated at this location during the earthquake (Fulton et al. 2013).

The volumetric heat capacity of the four samples showed similar values for the upper three core samples but a significantly lower value for the deepest core sample (Table 2 and Figure 4C). The deepest core sample within lithologic unit 5 (brown mudstone) consists mainly of subducting pelagic clays and clearly shows a lower grain density, suggesting a different solid composition, for example, more clay minerals and volcaniclastic grains. It is considered that the lower volumetric heat capacity and higher thermal diffusivity of the deepest core sample could be attributed to these differences. The average and standard deviation of the three deepest samples is $2.80 \pm 0.32 \mathrm{MJm}^{-3} \mathrm{~K}^{-1}$, and this range of values was used in the inversion of the analysis of the JFAST observatory frictional heat anomaly (Fulton et al. 2013).

Very slight differences were seen between the anisotropic measurements of thermal conductivity and thermal diffusivity in both the axial and radial directions. The maximum difference of the average values of thermal conductivity in both directions was $0.04 \mathrm{Wm}^{-1} \mathrm{~K}^{-1}$, corresponding 
to approximately $4 \%$ of their thermal conductivity values of approximately $1 \mathrm{Wm}^{-1} \mathrm{~K}^{-1}$ for the no. 2 sample. These values are less than the $5 \%$ level of measurement precision in the anisotropic measurement mode. In addition, the differences between thermal diffusivity in the two directions were similar. In theory, the anisotropic features of thermal diffusivity should be similar to those of thermal conductivity because the volumetric heat capacity is a scalar. It is therefore considered that anisotropy of no more than 5\% exists in the thermal conductivity and thermal diffusivity of the four JFAST core samples.

The thermal conductivities determined independently by the transient plane heat source method (hot disk), transient line heat source method (TeKa half-space probe), and the steady-state divided bar method are consistent with each other. A section of borehole with a distinctly lower thermal conductivity would result in a higher thermal gradient, and therefore a positive temperature anomaly. However, no large systematic changes in thermal conductivity were observed in the hanging wall and footwall mudstones (lithologic units 2 to 6 from 648.0 to $833.5 \mathrm{mbsf}$ ), corresponding with the depth range of closely spaced temperature sensors used within the JFAST observatory. However, there are notable exceptions to the relatively similar thermal conductivities, for example, in the chert samples (lithologic unit 7) from the bottom of the depth range cored (at site C0019), which were found to have a much higher thermal conductivity owing to a different mineralogy. In addition, the high-porosity slope sediment samples (lithologic unit 1) were found to have a slightly lower thermal conductivity and thermal diffusivity compared to the mudstone units (lithologic units 2 to 6), but with a similar volumetric heat capacity (Table 3). Thermal properties are recognized to be dependent on both the mineral composition of the rocks and their porosity.
Estimation of thermal diffusivity using thermal conductivity at JFAST site Correlation between thermal conductivity and thermal diffusivity

If there is no drastic change in the volumetric heat capacity of rocks (which is mainly dependent on mineral composition and porosity) within the same geologic formation or lithologic unit, then the values of both volumetric heat capacity and thermal conductivity can be used to derive thermal diffusivity. Several equations have previously been proposed to derive empirical relations between thermal conductivity and thermal diffusivity for ocean sediments and sedimentary rocks:

$$
\alpha=3.65 \lambda-0.7
$$

(Von Herzen and Maxwell 1959)

$$
\alpha=10 \lambda /\left(5.79-3.67 \lambda+1.016 \lambda^{2}\right)
$$

(Hyndman et al. 1979)

$$
\alpha=-0.176+2.284 \lambda+0.763 \lambda^{2}
$$

(for clay by Goto and Matsubayashi 2008)

$$
\alpha=-0.279+2.659 \lambda+0.434 \lambda^{2}
$$

(for sand by Goto and Matsubayashi 2008)

where $\lambda$ is measured in $\mathrm{Wm}^{-1} \mathrm{~K}^{-1}$, and $\alpha$ is measured in $10^{-7} \mathrm{~m}^{2} \mathrm{~s}^{-1}$. We therefore applied these equations to our hot disk measurement data of thermal conductivity and thermal diffusivity (Figure 5). Results showed that Equation 3 gave the best fit, particularly for the three sample nos. 1 to 3 located in the hanging wall of the frontal plate interface. Because the three thermal properties have a simple relation to that shown in Equation 1, the estimation of thermal diffusivity $\alpha$ from thermal con-

\begin{tabular}{|c|c|c|c|c|c|c|}
\hline \multirow{2}{*}{$\begin{array}{l}\text { Lithologic } \\
\text { unit }^{\text {a }}\end{array}$} & \multirow{2}{*}{$\begin{array}{l}\text { Depth interval of } \\
\text { the unit (mbsf) }\end{array}$} & \multirow{2}{*}{$\begin{array}{l}\text { Depth interval of samples } \\
\text { in the unit (mbsf) }\end{array}$} & \multirow{2}{*}{$\begin{array}{l}\text { Number } \\
\text { of data }\end{array}$} & \multicolumn{3}{|c|}{ Bulk measurement values (TC) and predicted values (TD and VHC) } \\
\hline & & & & $\mathrm{TC} \mathrm{Wm}^{-1} \mathrm{~K}^{-1}$ & TD $10^{-7} \mathrm{~m}^{2} \mathrm{~s}^{-1}$ & VHC MJm ${ }^{-3} \mathrm{~K}^{-1}$ \\
\hline 1 & $176.5-185.2$ & 176.8-183.1 & 4 & $0.94 \pm 0.09$ & $3.02 \pm 0.46$ & $3.15 \pm 0.21$ \\
\hline 2 & $648.0-659.7$ & $648.5-656.6$ & 7 & $1.18 \pm 0.10$ & $4.10 \pm 0.54$ & $2.89 \pm 0.14$ \\
\hline 3 & $688.5-820.1$ & $688.8-819.0$ & 50 & $1.16 \pm 0.08$ & $3.99 \pm 0.40$ & $2.91 \pm 0.10$ \\
\hline 4 & $821.5-822.5$ & $822.1-822.3$ & 4 & $1.16 \pm 0.09$ & $4.01 \pm 0.48$ & $2.91 \pm 0.12$ \\
\hline 5 & $824.0-832.9$ & $824.0-832.5$ & 13 & $1.14 \pm 0.06$ & $3.99 \pm 0.31$ & $2.88 \pm 0.15$ \\
\hline 6 & $832.9-833.5$ & $833.0-833.4$ & 4 & $1.08 \pm 0.06$ & $3.60 \pm 0.32$ & $3.01 \pm 0.09$ \\
\hline 7 & $833.5-836.8$ & 833.6-836.8 & 5 & $1.40 \pm 0.17$ & $5.29 \pm 0.89$ & $2.67 \pm 0.16$ \\
\hline
\end{tabular}
ductivity $\lambda$ is essentially the same as assuming an equation

Table 3 Measured results of thermal conductivities and estimated values of thermal diffusivities and volumetric heat capacities

aLithologic units are comprised as follows: unit 1, slope facies or wedge sediments; 2 , brown and bluish gray mudstone; 3 , gray mudstone; 4 , sheared clay; 5 , brown mudstone; 6 , pelagic clay; and 7, chert. Because the coring used was not continuous, the depth intervals of lithologic units recognized by the core description are not continuous (Expedition 343/343T Scientists 2013c).

${ }^{\mathrm{b}} \mathrm{TC}$, thermal conductivity; TD, thermal diffusivity; VHC, volumetric heat capacity were shown in a form of average and one standard deviation. TC is calculated from measured data by all the three methods (Figure 4A), but TD and VHC from the estimated values and measured values using the hot-disk method (Figure $6 \mathrm{~A}, \mathrm{~B}$ ). 


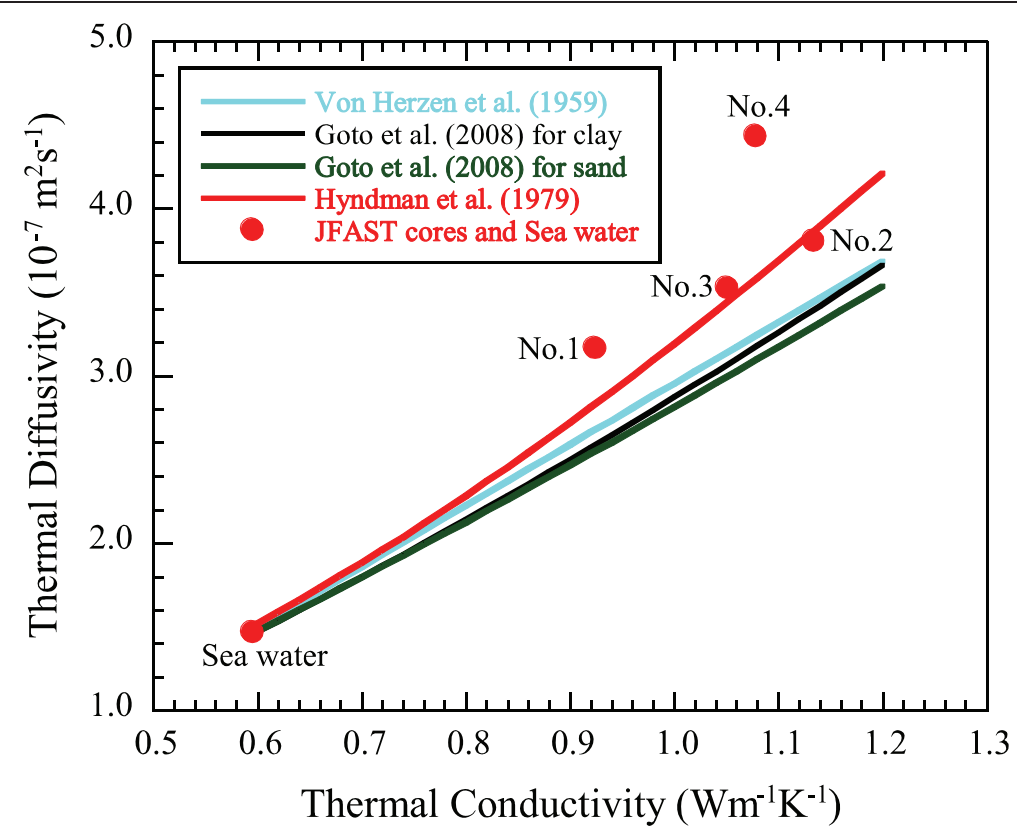

Figure $\mathbf{5}$ Cross plots of thermal diffusivity and thermal conductivity. The values (red circles) were measured using the hot-disk method in four whole-round core samples from JFAST and in sea water after Kaye et al. (1986). Curves are the empirical equations proposed previously for ocean sediments and sedimentary rocks.

of volumetric heat capacity $C$ for a rock/sediment sample population. Hyndman et al. (1979) proposed the above Equation 3 for marine sediments using measured thermal conductivity values (over tens) of turbidite and hemipelagic sediment samples from the Juan de Fuca ridge in the east Pacific. In addition, they calculated the volumetric heat capacity using a grain-specific heat (the specific heat capacity per unit mass) of the sediments without pore (approximately $760 \mathrm{Jkg}^{-1} \mathrm{~K}^{-1}$ ) using the method by Bullard (1954), and the water content values of sediments using the method by Ratcliffe (1960). The specific heat capacity used in the study of Hyndman et al. (1979) was therefore considered suitable for use with the materials of our core samples retrieved from the JFAST borehole in the west Pacific.

\section{Estimation of thermal diffusivity}

We applied Equation 3 to the 83 values of thermal conductivity determined using the transient line heat source method (Expedition 343/343T Scientists 2013b) and divided bar method (Fulton et al. 2013) to estimate thermal diffusivity at the JFAST site (Figure 6A). These values generally agree with the four measured values reported in this study and show a slight increase with depth. We use Equation 1 to estimate the volumetric heat capacity for the 83 measured values of thermal conductivity (Figure 6B). Overall, the average values of the three thermal conductivities independently measured by the three methods in lithologic units 2 to 5 are similar; however, the values are clearly different in units 1 (where samples have higher porosity) and 7 (which consists of chert and has a radically different mineralogy) (Table 3).

The estimated thermal diffusivity is seen to increase slightly with depth in the hanging wall of the plate boundary fault, and in contrast, the calculated volumetric heat capacity decreases slightly with depth (Figure 6). Equation 3 shows a particularly good fit to the measured data for the three shallower samples, and thus we have more confidence in the estimated values of thermal diffusivity and volumetric heat capacity in the hanging wall. It is, however, considered possible that the values of thermal diffusivity and volumetric heat capacity below the plate boundary fault could be underestimated and overestimated, respectively, because of poorer fitting for the deepest of our four samples (Figure 5).

\section{Summary}

We determined thermal conductivities, thermal diffusivities, and volumetric heat capacities using a transient plane heat source method at atmospheric pressure, in room-temperature conditions, and in a fully saturated state. The four whole-round core samples used were obtained as part of the Japan Trench Fast Drilling Project (JFAST), with the primary objective of interpreting the frictional heat signal from slip during the 2011 (Mw 9.0) Tohoku-Oki earthquake in terms of coseismic friction (Fulton et al. 2013). Characterization of all three thermal 


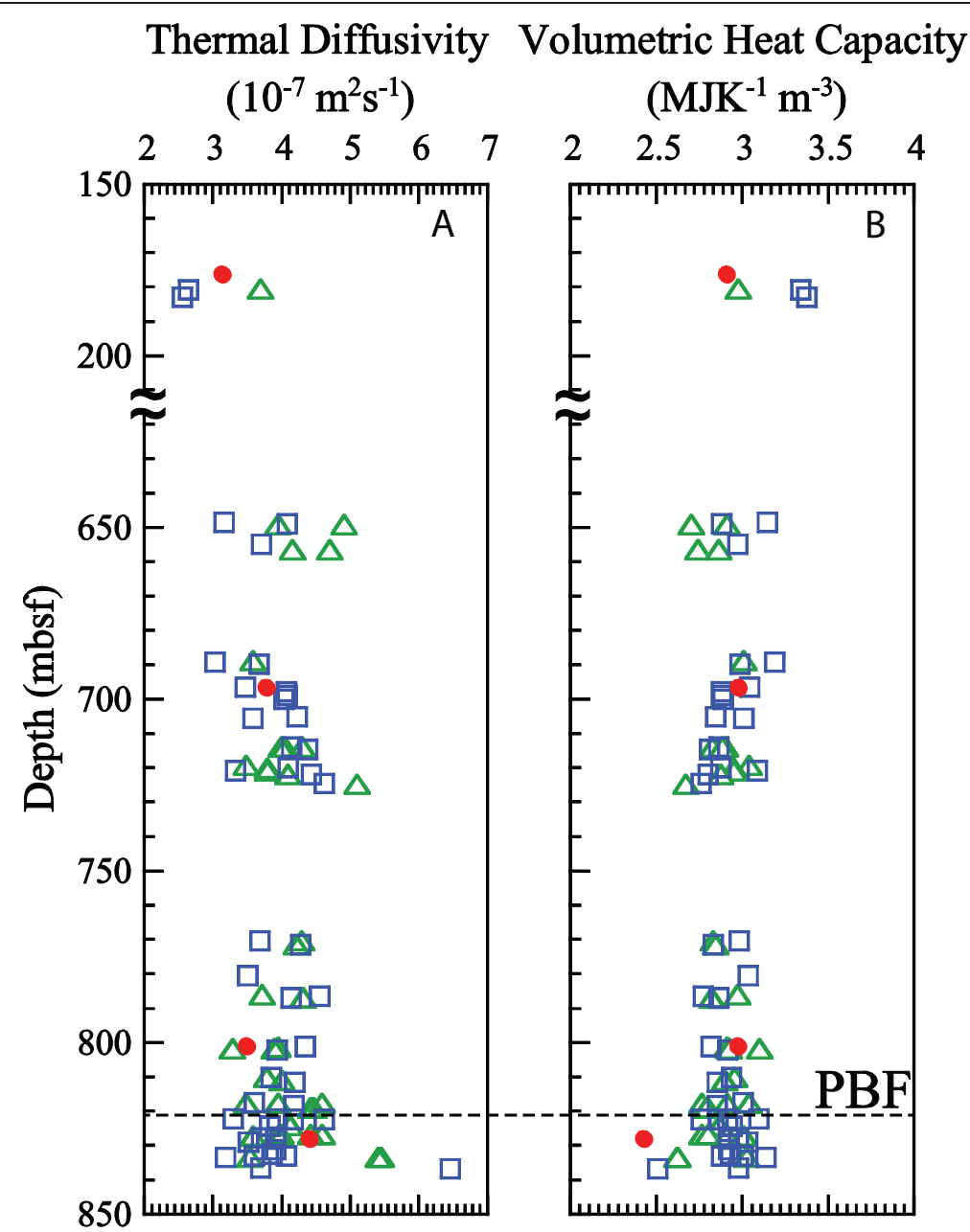

Figure 6 Depth profiles of thermal diffusivity (A) and volumetric heat capacity (B). Thermal diffusivity (A) was estimated using the empirical equation proposed by Hyndman et al. (1979) from the measured thermal conductivities of 45 half-core samples (open squares) and 38 rock-chips samples (open triangles), and the measured values for the four whole-round core samples (red circles). Volumetric heat capacity (B) was calculated using the measured thermal conductivity and estimated thermal diffusivity (open squares and triangles) and calculated using both measured values (red circles). Red circles in (A) and (B) are the same as those used in Figure 4. The broken lines and PBF also represent the same as in Figure 4.

properties is important for properly interpreting the detected temperature anomaly in the vicinity of the plate boundary fault and for the analysis of other thermal processes observed within the JFAST observatory temperature data. The measured thermal conductivities were found to be consistent with those independently measured using a transient line source method for 45 half-core samples in an onboard laboratory and using a divided bar technique on 38 rock-chips samples in a shore-based laboratory. We examined several previously proposed empirical equations describing relationships between thermal diffusivity and thermal conductivity for ocean sediments, by applying our data obtained from using the transient plane heat source method. We then used these results to estimate the thermal diffusivities and the volumetric heat capacities of the 45 half-core samples and 38 rock-chips samples by their thermal conductivities, covering the whole-cored depth range of the JFAST borehole. Our measurements reveal less than $5 \%$ anisotropy in terms of thermal conductivity and thermal diffusivity (the detectable limit of the measurement apparatus). The extrapolations suggest little variation in any of the three thermal properties within several tens of meters above the plate boundary fault (where a $0.31^{\circ} \mathrm{C}$ temperature anomaly has been observed). The parameters used to model and interpret this signal in terms of coseismic frictional heating utilized the measurement values presented here. Our extrapolation of thermal diffusivity and volumetric heat capacity from empirical relationships with thermal conductivity suggests that the range of values used in the modeling are reasonable, as is the assumed general uniformity of values within the mudstones from approximately 800 to 820 mbsf. 
Characterization of the three thermal properties and their possible variation with depth provides important constraints for further investigations of other thermal processes observed within the JFAST temperature observatory. For example, Fulton et al. (2013) reported that the characteristic recovery time of the drilling disturbance within the JFAST temperature data is spatially variable, with larger recovery times at around 765,800 , and 810 mbsf. These regions were thus interpreted as permeable zones with a greater infiltration of drilling fluids. Although further analysis is warranted and ongoing, our depth profiles of thermal properties reveal no large spatial variations that would obviously account for these observations, suggesting instead that they may indeed be influenced by the hydrogeologic structure.

The JFAST temperature data has provided a remarkable window into the subsurface thermal field across the plate boundary fault, at a time period of 16 to 25 months after the $2011 \mathrm{Mw} 9.0$ Tohoku-Oki earthquake. It is considered that characterization of the thermal property structure within the subsurface provides a context for further investigations into the hydrologic and thermal signals observed within the JFAST temperature data and the constraints on models of frictional heating and other thermal processes within the shallow subduction zone.

\section{Competing interests}

The authors have no competing interests to declare.

\section{Authors' contributions}

The manuscript was composed by WL, PF, RH, and MK, who also prepared the figures. The hot disk experiments were designed and performed by $\mathrm{WL}$, $\mathrm{OT}$, and WT, who also performed the density/porosity measurements. PF carried out the TeKa probe tests in the onboard laboratory, and RH performed the divided bar tests in the onshore laboratory. OM performed the model calculation. All authors contributed to the scientific discussions. All authors read and approved the final manuscript.

\section{Acknowledgements \\ The core samples used in this study were provided by IODP expedition 343 The authors gratefully acknowledge the support provided by the Expedition 343/343T Scientists, D/V Chikyu drilling crew, and laboratory technicians. Part of this work was supported by Grants-in-Aid for Scientific Research 21107006 (MEXT) and 25287134 (JSPS), Japan. PF was supported by the US Science Support Program of IODP and the Gordon and Betty Moore Foundation.

\begin{abstract}
Author details
'Kochi Institute for Core Sample Research, Japan Agency for Marine-Earth Science and Technology (JAMSTEC), 200 Monobe-otsu, Nankoku, Kochi, 783-8502, Japan. ${ }^{2}$ Department of Earth and Planetary Sciences, University of California, Santa Cruz, CA, 95064, USA. ${ }^{3}$ College of Oceanic and Atmospheric Sciences, Oregon State University, Corvallis, OR, 97331, USA. ${ }^{4}$ Marine Works Japan LTD, Nankoku, Kochi, 783-8502, Japan. ${ }^{5}$ Institute for Geo-Resources and Environment, National Institute of Advanced Industrial Science and Technology (AIST), Tsukuba, Ibaraki, 305-8566, Japan.
\end{abstract}

Received: 26 February 2014 Accepted: 20 May 2014

Published: 5 June 2014

\section{References}

Argus DF, Gordon RG, DeMets C (2011) Geologically current motion of 56 plates relative to the no-net-rotation reference frame. Geochem Geophys Geosyst 12, Q11001, doi:10.1029/2011GC003751
Bullard EC (1954) The heat flow of heat through the floor of the Atlantic Ocean. In: Proceedings of Royal Society, vol A, 222. Royal Society, London, pp 408-429, doi:10.1098/rspa.1954.0085

Chester FM, Mori JJ, Toczko S, Eguchi N, Expedition 343/343T Scientists (2012) Integrated ocean drilling program expedition 343/343T preliminary report. Japan Trench Fast Drilling Project (JFAST). doi:10.2204/iodp. pr.343343T.2012

Chester FM, Rowe C, Ujiie K, Kirkpatrick J, Regalla C, Remitti F, Moore JC, Toy V, Wolfson-Schwehr M, Bose S, Kameda J, Mori J, Brodsky EE, Eguchi N, Toczko S, Expedition 343 and 343T Scientists (2013) Structure and composition of the plate-boundary slip zone for the 2011 Tohoku-Oki earthquake. Science 342:1208-1211, doi:10.1126/science.1243719

Expedition 343/343T Scientists (2013a) Expedition 343/343T summary. In: Chester FM, Mori J, Eguchi N, Toczko S, Expedition 343/343T Scientists (eds) Proceedings of the IODP, vol 343/343T. Integrated Ocean Drilling Program Management International, Inc, Tokyo, doi:10.2204/iodp.proc.343343T.101.2013

Expedition 343/343T Scientists (2013b) Methods. In: Chester FM, Mori J, Eguchi N, Toczko S, Expedition 343/343T Scientists (eds) Proceedings of the IODP, vol. 343/343T. Integrated Ocean Drilling Program Management International, Inc, Tokyo, doi:10.2204/iodp.proc.343343T.102.2013

Expedition 343/343T Scientists (2013c) Site C0019. In: Chester FM, Mori J, Eguchi N, Toczko S, Expedition 343/343T Scientists (eds) Proceedings of the IODP, vol. 343/ 343T. Integrated Ocean Drilling Program Management International, Inc, Tokyo, doi:10.2204/iodp.proc.343343T.103.2013

Fujiwara T, Kodaira S, No T, Kaiho Y, Takahashi N, Kaneda Y (2011) The 2011 Tohoku-Oki earthquake: displacement reaching the trench axis. Science 334:1240, doi:10.1126/science.1211554

Fulton PM, Brodsky EE, Kano Y, Mori J, Chester F, Ishikawa T, Harris RN, Lin W, Eguchi N, Toczko S, Expedition 343, 343T, and KR13-08 Scientists (2013) Low coseismic friction on the Tohoku-Oki fault determined from temperature measurements. Science 342:1214-1217, doi:10.1126/science.1243641

Goto S, Matsubayashi O (2008) Inversion of needle-probe data for sediment thermal properties of the eastern flank of the Juan de Fuca Ridge. J Geophys Res 113, B08105, doi:10.1029/2007JB005119

Gustafsson SE (1991) Transient plane source techniques for thermal conductivity and thermal diffusivity measurements of solid materials. Rev Sci Instrum 62:797-804

Horai K, Simons G (1969) Thermal conductivity of rock-forming minerals, Earth Planet Sci. Lett 6:359-368

Horai K, Susaki J (1989) The effect of pressure on the thermal conductivity of silicate rocks up to $12 \mathrm{kbar}$. Phy Earth Planetary Inter 55:292-305

Hot Disk (2007a) Instruction manual, hot disk thermal constants analyserSoftware Version 5.9. p 42. Hot Disk Inc., Gothenburg, Sweden

Hot Disk (2007b) Instruction manual, anisotropic application, hot disk thermal constants analyser-software version 5.9. 42. Hot Disk Inc, Gothenburg, Sweden

Hyndman RD, Davis EE, Wright JA (1979) The measurement of marine geothermal heat flow by a multipenetration probe with digital acoustic telemetry and in situ thermal conductivity. Mar Geophys Res 4:181-205, doi:10.1007/BF00286404

ISO (2008) Plastics-determination of thermal conductivity and thermal diffusivitypart 2: transient plane heat source (hot disc) method, International Standard ISO 22007-2. International Organization for Standardization, Geneva, Switzerland

Kaye GWC, Laby TH (1986) Tables of physical and chemical constants and some mathematical functions, 15th edn. Longman, London, p 477

Lay T, Ammon CJ, Kanamori H, Xue L, Kim MJ (2011) Possible large near-trench slip during the 2011 Mw 9.0 off the Pacific coast of Tohoku earthquake. Earth Planets Space 63:687-692, doi:10.5047/eps.2011.05.033

Lin W, Kwasniewski M, Imamura T, Matsuki K (2006) Determination of threedimensional in-situ stresses from anelastic strain recovery measurement of cores at great depth. Tectonophysics 426:221-228

Lin W, Tadai O, Hirose T, Tanikawa W, Takahashi M, Mukoyoshi H, Kinoshita M (2011) Thermal conductivities under high pressure in core samples from IODP NanTroSEIZE drilling site C0001. Geochem Geophys Geosyst 12: Q0AD14, doi:10.1029/2010GC003449

Lin W, Conin M, Moore JC, Chester FM, Nakamura Y, Mori JJ, Anderson L, Brodsky EE, Eguchi H, Expedition 343 Scientists (2013) Stress state in the largest displacement area of the 2011 Tohoku-Oki earthquake. Science 339:687-690, doi:10.1126/science.1229379

Mori JJ, Chester FM, Eguchi N, Toczko S (2012) Japan Trench Fast Earthquake Drilling Project (JFAST). IODP expedition 343 scientific prospectus. doi:10.2204/iodp.sp.343.2012, 343 
Ratcliffe EH (1960) The thermal conductivities of ocean sediments. J Geophys Res 65:1535-1541, doi:10.1029/JZ065i005p01535

Sass JH, Stone C, Munroe RJ (1984) Thermal conductivity determinations on solid rock-a comparison between a steady-state divided bar apparatus and a commercial transient line-source device. Jour Volcanol Geotherm Res 20:145-153

Von Herzen RP, Maxwell AE (1959) The measurement of thermal conductivity of deep-sea sediments by a needle-probe method. J Geophys Res 64:1557-1563, doi:10.1029/JZ064i010p01557

Yang T, Mishima T, Ujiie K, Chester FM, Mori JJ, Eguchi N, Toczko S, Expedition 343 Scientists (2013) Strain decoupling across the décollement in the region of large slip during the 2011 Tohoku-Oki earthquake from anisotropy of magnetic susceptibility. Earth Planet Sci Lett 381:31-38, dx.doi.org/10.1016/j. epsl.2013.08.045

doi:10.1186/1880-5981-66-48

Cite this article as: Lin et al.: Thermal conductivities, thermal

diffusivities, and volumetric heat capacities of core samples obtained from the Japan Trench Fast Drilling Project (JFAST). Earth, Planets and

Space 2014 66:48

\section{Submit your manuscript to a SpringerOpen ${ }^{\circ}$} journal and benefit from:

- Convenient online submission

- Rigorous peer review

- Immediate publication on acceptance

- Open access: articles freely available online

- High visibility within the field

- Retaining the copyright to your article

Submit your next manuscript at $\gg$ springeropen.com 